\title{
ECONOMETRIC MODELING OF SECONDARY RESOURCES OF IRON
}

\author{
Yu. B. Sayadova', P. I. Chernousov' ${ }^{1}$, O. V. Golubev ${ }^{1}$ \\ ${ }^{1}$ National University of Science and Technology “MISiS”(Moscow, Russia)
}

E-mail: shadowdomenika@rambler.ru; p.chernou@yandex.ru; olega-san@yandex.ru

\section{AUTHOR'S INFO}

Yu. B. Sayadova, Post-graduate, Dept. of Energy-Efficient and Resource-Saving Industrial Technologies, P. I. Chernousov, Cand. Eng., Associate Prof., Dept. of EnergyEfficient and Resource-Saving Industrial Technologies, O. V. Golubev, Cand. Eng., Associate Prof., Dept. of EnergyEfficient and Resource-Saving Industrial Technologies

\section{Key words:}

modeling, secondary resources, recycling, retro prognosis, spheres of consumption, metal products, scrap, program complex

\begin{abstract}
A B S T RACT
The lack of natural iron-containing resources causes an increased interest in secondary materials. The article is devoted to the formation of the approach to the sound recycling of metal containing products. The article discusses options for the approach, organized abroad and based on the analysis of the man-caused elemental stream, the search for ways to involve secondary resources in production. Particular attention is paid to the place of retro prognosis in the analysis of the man-caused elemental stream carried out by means of computer simulation in the conditions of the region under consideration. In determining the volume of secondary material formation becomes possible to competently plan their involvement in production. Planning for the long-term perspective is much more convenient to carry out with the help of the computing power of the computer. In the Russian Federation, this problem has been little studied and requires further research.
\end{abstract}

\section{Introduction}

Utilization of secondary raw materials allows effectively maintain the performance of the metallurgical industry with less involvement of natural raw materials. The advanced global experience of the last decades shows that only a competent application of the methodology for managing secondary resource flows, as well as the ability to manage them for the long term, will allow the metallurgy to be transferred to an innovative development path. In addition, the saturation of all spheres of human life with metal-containing products poses the task of constructing a recycling process so that the recycling of scrap metal is justified and production based on secondary raw materials is developed. To organize such a method of circulation requires a systematic view on secondary resources, taking into account industrial, environmental and economic factors. At the same time, the use of resources of secondary metals should be justified for the long term. The complex approach can be critical to meet the growing demand for metal-containing resources in the future [1-3].

After exploring iron ore deposit, the extraction of natural resources begins, as well as the life cycle of the metal and metal-containing products. The circulation time of such products is quite long (especially for some types of products) and runs from mining through processing and manufacturing of products and finish at the end of use and recycling. The specific application time of products depends on numerous factors and for different products varies within wide limits. Thus, in the case of attempts to build a life-cycle model is obtained sufficiently large database.

To inculcate a culture of correct use of recycled resources used the multicomponent model of recycling, taking into account all stages of the life cycle of products containing metal. Emphasize that the main theme of the UNEP report [4] according to the analysis of advanced technologies in the industry is «Modeling metals recycling». The issue of including the optimal methods of collecting and sorting metal products in the recycling chain is discussed. It is noted that in the last decade in order to solve such problems in advanced industrial countries actively developed and tested software packages.

For well-written forecast scenarios of development of metallurgy, export, import and consumption of metal are necessary to have a database on a cycle of metal products in the past. The authors of the study [5] have developed a dynamic model to estimate the number of secondary resources of ferrous metals, suitable for recycling. An analysis of changes in the overall ecological burden on the environment until 2030 was made, taking into account the maximum involvement of secondary resources. According to the results of the assessment of the life cycle of the metal in the composition of metal products, several scenarios for the development of the ferrous metallurgy was recommended.

\section{Study background}

In the National University of Science and Technology «MISiS» the program complex «Simulation model of recycling» was developed and used in the educational process, which realized the possibility of optimizing the consumption of secondary resources of metals [6-9]. The methodology is based on the principle of optimization scenarios of production and operation of metal products, which depending on the duration of the life cycle that is divided into groups corresponding to the 


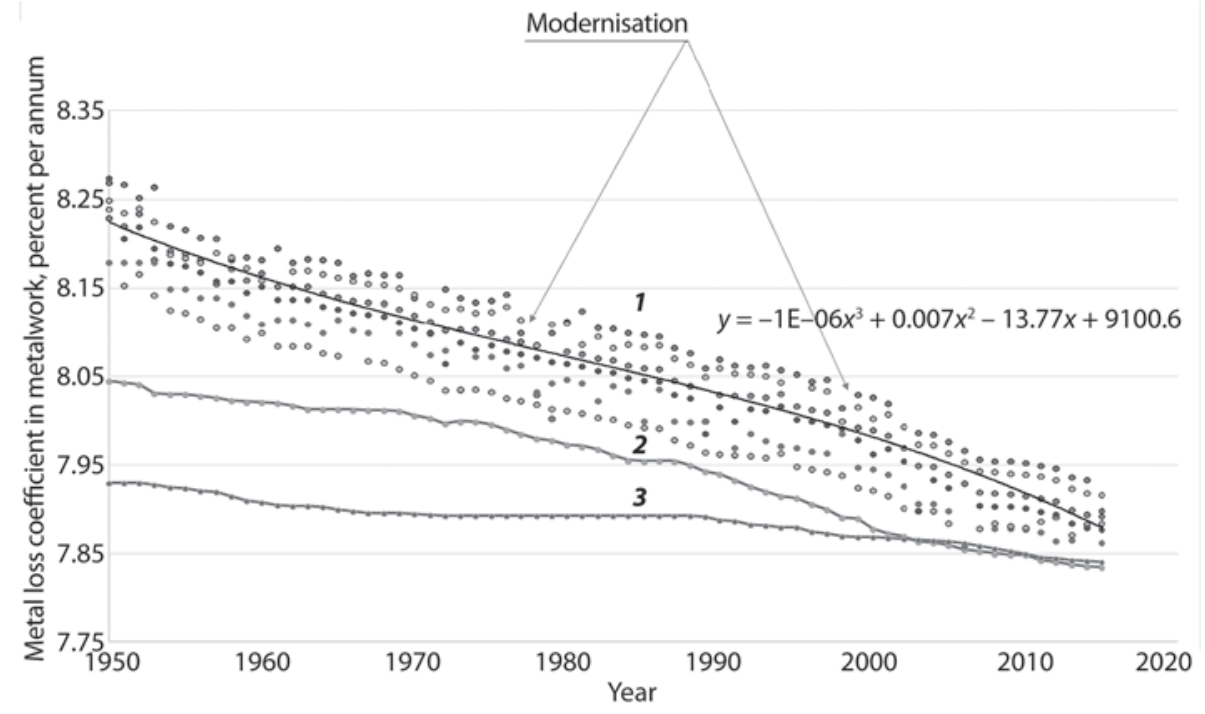

Fig. 1. Metal loss coefficient in metalwork of rolled steel: 1-Russia; 2-Japan; 3-Germany

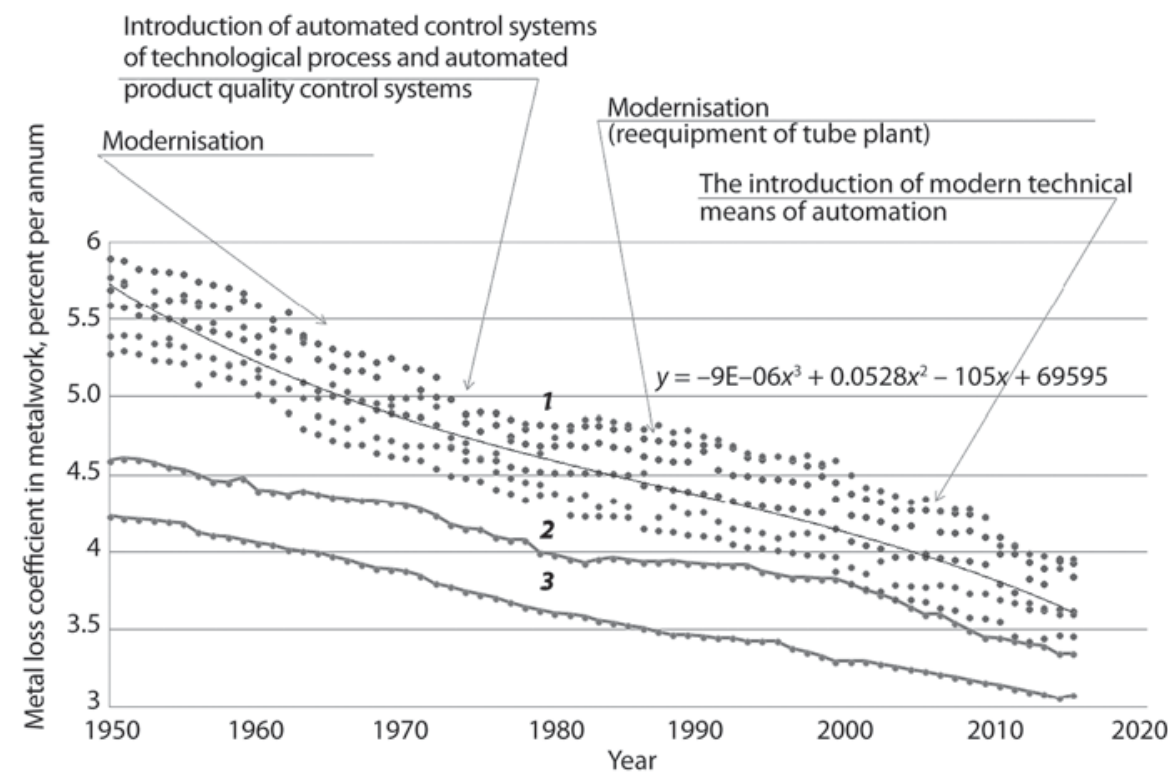

Fig. 2. Metal loss coefficient in metalwork of other types (tubes and etc.): 1-Russia; 2-Japan; 3-Germany

short, medium and long-term time interval. The analyzed flows of metal products are characterized by coefficients and functions that describe the distribution of iron and impurity elements into the environment, accumulation in technogenic deposits, foundations and other elements of the technosphere. The main calculation formulas of the described method are given in the source [9].

In this case variable collection involved in the calculation play a major role. The construction of the computational model begins with the determination of the geographical and economic boundaries of the object of study. At the same time, special attention is required for those conditions in which, during the period under re- view, there is a change in geographic boundaries and, as a result, the object of research must be defined and identified in advance.

The database of variables of the object of research is necessary for conducting a forecast on a finite time segment. The forecast period and the corresponding year of the beginning of the research are set independently. Thus, the retrospective database is formed for certain, selected and predetermined conditions.

In this study, the section of selection initial coefficients representing the greatest number of difficulties. In addition, an important factor is to obtain just such a database, which would be adequate to the object of study. Selection of the set of values of object variables is key in shaping the retrospective of the iron life cycle as part of products.

The division of the input stream into several components is an integral part of the study. This is necessary in view of the fact that a number of coefficients, such as the coefficient of wear of metal products, the coefficient of losses during the collection of metal products, and others have different values for products of different groups. The division of the flow of products into several streams, depending on the duration of operation, is one of the conditions for ensuring good accuracy of calculation and, as a result, the consistency of the resulting data as a result. Despite the fact that this condition is important, it is not unique. Taking into account individual features of the considered and adopted to modeling region is extremely important. Due to the fact that the region under study is adopted both in the geographical and economic framework of the country, the consideration of export and import factors are important components.

The block of initial data for the calculation of retroforecast includes information on production, metalworking, domestic consumption, export, import for the period of research, starting from 1950. 


\section{Results}

To calculate the main forecasting parameters of recycling, according to the results of statistical studies, it is necessary to create a database on the production of metal products and metalworking for the period from 1950. In formation such database was taken into consideration the parameters of 28 articles of the annual Statistical Yearbook «External Economic Relations of the USSR» (until 1991, [10]) and official information of the Federal Customs Service (FCS of Russia) [11], as well as [12]. The importance of the proper choice of the initial information for the implementation of long-term prognosis of secondary metal resource materials research indicates both foreign and domestic authors [13, 14]. The dynamics of changes in metal loss during metalworking for different groups of products is illustrated by the graphs shown in Fig. $\mathbf{1}$ and 2. In the graphs, the mean values of the analyzed parameters were obtained and shown the corresponded functional equations. Without taking into account other factors, the forecast will be based on the trend line and will not have sufficient information content for this study. In this regard, in the preparation of forecast scenarios and data-processing, program complex «Simulation model of recycling» will be used, which allows to analysis considering other indicators of the product lifecycle.

The largest influence on the change in loss coefficient of metal in metalworking production has the introduction of new and modernization of existing manufacturing facilities. Replacement of obsolete equipment with modern helps to reduce metal loss. In addition, it contributed to the adaptation of non-destructive testing methods in the process. This will keep the products that were previously inevitable as a loss.

Consistent integration of computer opportunities in non-destructive control of the process is also making improvements through production operation. A significant impact on the quality of products provides the implementation of an automated control system. In the production, remain technologically inevitable loss of metal occurs and accordingly the search for optimal solutions of the technological process.

\section{Conclusions}

Designed in National Research Technological University «MISiS» program complex enables to optimize the consumption of secondary resource. The analyzed flows of metal products are characterized by coefficients and functions describing the distribution of iron and impurity elements into the environment, accumulation in technogenic deposits, foundations and other elements of the technosphere. Thus, at the present time in National Research technological University
«MISIS» created the conditions for research, forecasting and optimization of the use of secondary resources of ferrous metals in different geographical conditions of the Russian Federation.

\section{REFERENCES}

1. Degel R., Fröhling Ch., Hansmann T., Kappes H., Barozzi S. The concept of waste-free fabrication of metallurgical products. Chernye metally. 2016. No. 4. pp. 40-49.

2. Brunner Ch., Schwelberger J., Fleischanderl A., Ropke A. Practice of recycling operations in iron direct reduction units. Chernye metally. 2017. No. 8. pp. 59-63.

3. Leushin I. O., Subbotin A. Yu., Geyko M. A. Recycling of galvanized steel scrap for use in cast iron melting in induction melting facilities. CIS Iron and Steel Review. 2015. Vol. 10. pp. 19-22.

4. Reuter M. A., Hudson C., van Schaik A., Heiskanen K., Meskers C., Hagelüken C. UNEP Metal Recycling: Opportunities, Limits, Infrastructure, A Report of the Working Group on the Global Metal Flows to the International Resource Panel. 2013. $318 \mathrm{p}$.

5. Daigo I, Fujimaki D., Matsuno J., Adati E. Building a dynamic model for analyzing the load on the environment during the reverse use of metal products. CAMP-ISIJ. 2005. No. 14.

6. Korotchenko A. S., Korotchenko N. A., Chernousov P. I. Certificate state registration of computer programs 2013660195, Russian Federation. Computer training program - simulator "Simulation model of recycling" (rightsholder is the Federal State Educational Institution NUST "MISIS"). Computer programs, databases, topologies of integrated circuits 2013. No. 4. Date arrived 07.05.2013; date registered 10.28.2013. $298 \mathrm{p}$.

7. Chernousov P. I., Korotchenko A. S., Ryabova A. V. Analysis, monitoring, and prediction of the use of secondary sources of iron in recycling society. Metallurgist. 2010. Vol. 54. No. 3-4. pp. $144-152$.

8. Golubev O. V., Korotchenko A. S., Chernousov P. I. Predictions of scenarios for the consumption of scrap metal in ferrous metallurgy. Metallurgist. 2011. Vol. 54. No. 9-10. pp. 649-659.

9. Chernousov P. I. Recycling. Technologies for processing and utilization of technogenic formations and wastes in the ferrous metallurgy. M.: Izdatelskiy dom MISiS. 2011. 428 p.

10. External Economic Relations of the USSR. Annual Statistical Yearbook. «Finansy i statistika». [Electronic resource]. URL: http://istmat.info/node/21347.

11. Federal Customs Service: [Electronic resource]. URL: http:// www.customs.ru/index.php?option $=$ com_content\&view $=$ art icle \&id $=7995 \&$ Itemid $=1845$.

12. Kalabekov I. G. The USSR and the countries of the world in numbers. Reference edition. Moscow. 2015. 239 p.

13. Zaparyi V. V., Shimov V. V., Chernousov P. I. Forecast scenarios for the development of ferrous metallurgy in the field of scrap consumption. Metallurg. 2016. No. 7. pp. 7-10.

14. van Schaik A., Reuter M. A. Recycling indices visualizing the performance of the circular economy. World of Metallurgy ERZMETALL. 2016. Vol. 69 (4). pp. 201-216. 